\title{
Hereditary Colorectal Cancer in China
}

\author{
Zheng Shu, Huang Yanqin, Yuan Ying \\ Cancer Institute, Second Affiliated Hospital, Zhejiang University, Hangzhou, People's Republic of China
}

Key words: colorectal cancer, hereditary cancer syndrome, hereditary nonpolyposis colorectal cancer, familial adenomatous polyposis, China

Corresponding author: Professor Dr. Zheng Shu, scientific director, Cancer Institute, Second Affiliated Hospital, Zhejiang University, Hangzhou, People's Republic of China, tel. 0086-0571-87784501, e-mail: zhengshu@zju.edu.cn.

Web site: www.ziu.edu.cn/english/resources/hospitals/2nd.htm

Submitted: 5 November 2005

Accepted: 11 November 2005

\begin{abstract}
The purpose of this article is to review basic research as well as clinical studies on Chinese hereditary colorectal cancer. Hereditary nonpolyposis colorectal cancer (HNPCC, Lynch syndrome) accounts for $2.2 \%$ of all colorectal cancer, and Chinese criteria for suspected HNPCC have been developed. Germline mutations as well as large genomic rearrangements of mismatch repair (MMR) genes are responsible for this syndrome. Gastric cancer is the second most common cancer in Chinese HNPCC patients. Contrary to sporadic colorectal cancer in the Chinese population, HNPCC does not typically present with rectal cancer. Incidence of familial adenomatous polyposis (FAP) in China is approximately 1.5/100,000. Polyps in Chinese FAP patients can emerge as early as 16 months old, but malignant transformation usually occurs in the third and fourth decade. Total resection of the colon and rectum is necessary in FAP patients. For unresectable duodenal polyps, chemopreventive agents may be used.
\end{abstract}

\section{Introduction}

According to the IACR (International Association of Cancer Registries) [1], in the year 2002, 150,956 new cases of colorectal cancer (CRC) were expected to occur in China, while the age-standardised incidence of colorectal cancer would be 13.6/100,000 in men and $9.3 / 100,000$ in women. These predictions were derived from cancer statistics of six separate areas in China from 1993 to 1997. However, in 1999 colorectal cancer incidence in Shanghai, the biggest city in China included in the IARC's estimates, had already reached $16.2 / 100,000$ in men and 14.5/100,000 in women [2], more than a one-fold increase compared with the 1972-1974 period [3]. Shanghai has witnessed the highest and fastest growing colorectal cancer incidence in China. It is a fact that the incidence of colorectal cancer in China is increasing rapidly.

Genetic alterations as well as environmental influences are thought to underlie the development of all colorectal malignancies. In general, environmental changes play a critical role in the rapid growth of colorectal cancer incidence, while the contribution of genetic alterations that cause hereditary colorectal cancer is probably relatively stable. Although there are no statistics available on the incidence of hereditary colorectal cancer in China as a whole, we expect that the incidence of hereditary colorectal cancer in China is growing due to the changing environment as well as to more diagnosed cases because of more clearly specified diagnostic criteria. According to Lynch et al. 
[4], approximately $20 \%$ of all patients with colorectal cancer carry a familial risk, with $5-10 \%$ inherited as a Mendelian trait. Hereditary colorectal cancer can be broadly classified into two categories based on the presence or absence of multiple colorectal polyps: polyposis syndromes and nonpolyposis syndromes. The former can be further divided on the basis of histologic criteria into adenomatous-like FAP and hamartomatous syndromes like juvenile polyposis and Peutz-Jeghers syndrome. This article will review clinical and basic research on both types of hereditary colorectal cancer syndromes in China, focusing on the differences with Western countries and particular characteristics of Chinese hereditary colorectal cancer. Relevant new issues on hereditary colorectal cancer outside China will also be discussed.

\section{Hereditary nonpolyposis colorectal cancer (HNPCC)}

HNPCC, which some prefer to refer to as Lynch syndrome, is an autosomal dominant inherited cancer syndrome caused by germline mutations of mismatch repair (MMR) genes. This disorder is characterised by early onset of colorectal cancer and other malignancies including gastric, endometrial, ovarian, ureter, renal pelvis, hepatobiliary tract and small bowel cancer. When the name Lynch syndrome was first coined by Borland in 1984 [5], a Lynch family with five cases was reported in the same year in a Chinese medical journal [6], but it was not until 1998 that a series of Chinese HNPCC families began to be studied [7]. Several research groups in China have been devoted to collecting and studying Chinese Lynch families. With their effort, clinical and molecular research on HNPCCs in China has been greatly accelerated.

\section{Clinical diagnosis}

The diagnostic criteria for HNPCC continue to evolve as the understanding and characteristics of this heterogeneous disorder improve. The Amsterdam criteria, which were established in 1990 and revised in 1999, have been the classical diagnostic criteria of HNPCC. Based on the Amsterdam criteria, HNPCC in China accounts for $2.2 \%$ of all colorectal cancer [8]. However, the Amsterdam criteria are too strict for diagnostic purposes or for exclusion of patients from further work-up. More importantly, they do not account for patients from small families, which is a common phenomenon in China. With these deficiencies in mind, several sets of modified clinical criteria such as the
Bethesda criteria [9], revised Bethesda criteria [10], Japanese criteria [1 1] and Korean suspected criteria [12] have been proposed. The National Hereditary Colorectal Cancer Network of China proposed Chinese HNPCC criteria in 2003 [13]. Based on the Korean suspected criteria, Chinese HNPCC criteria have been modified as follows: at least two pathologically verified colorectal cancers in a family; at least two of them are first-degree relatives including parents or siblings; in addition, at least one of these conditions has to be satisfied: (1) at least one case develops multiple colorectal cancer, including adenomas, (2) at least one colorectal cancer is diagnosed before age 50, (3) at least one case with extracolonic malignancies including gastric, endometrial, small bowel, ureter and renal pelvis, ovarian, and hepatobiliary malignancies. The differences between Chinese criteria and other criteria are listed in Table 1.

\section{Genetics}

Since the discovery of the major human gene with DNA misrepair function in 1993-1995, mutations in MSH2, MLH1, MSH6 and PMS2 have been convincingly associated with HNPCC. According to the database maintained by the international collaborative group on HNPCC (International Society for Gastrointestinal Hereditary Tumor, InSiGHT), approximately 450 different HNPCC-associated mismatch repair gene mutations are known that primarily involve MLH1 ( 50\%), MSH2 ( $39 \%)$, and MSH6 ( 7\%) [14]. Most of these mutations are frameshift and nonsense mutations which are obviously pathogenic, but the roles missense mutations play are diversified. Some may be harmless single nucleotide polymorphisms, whereas others may contribute to cancer risks. Studying segregation of these mutations in affected and unaffected relatives, and functional assays, are among the methods to investigate the functional nature of these missense mutations. In addition to these point mutations, large genomic rearrangements of MMR genes have recently been reported to play an important role in the development of HNPCC. A systematic search of 439 HNPCC families for genomic rearrangements in MSH2, MLH1, MSH6 and PMS2 has identified 48 genomic rearrangements in 68 unrelated kindreds. Twenty-nine out of 48 were found in MSH2, 13 in MLH1, 2 in MSH6, and 4 in PMS2 [15].

For the purpose of presenting the genetic alterations in Chinese HNPCC families, eight doctorate studies [16-23] which aimed at germline mutation detection in Chinese HNPCC have been summarised. A total of 35 clinically diagnosed unrelated HNPCC families, most of them meeting Amsterdam criteria, have been 
Table 1. Comparison of clinical diagnostic criteria for HNPCC

\begin{tabular}{|c|c|c|c|c|c|}
\hline $\begin{array}{l}\text { Criteria ltems } \\
\text { colorectal } \\
\text { cancer patients }\end{array}$ & $\begin{array}{l}\text { Amsterdam criteria } \\
\text { (including I and II ) } \\
\geq 3 \text { (including } \\
\text { extracolonic tumours) }\end{array}$ & $\begin{array}{l}\text { Japanese } \\
\text { criteria A } \\
\geq 3\end{array}$ & $\begin{array}{l}\text { Chinese criteria } \\
\geq 2\end{array}$ & $\begin{array}{l}\text { Japanese } \\
\text { criteria B } \\
\geq 2\end{array}$ & $\begin{array}{l}\text { Bethesda } \\
\text { guidelines (2004) } \\
\geq 1\end{array}$ \\
\hline $\begin{array}{l}\text { first-degree } \\
\text { relatives }\end{array}$ & at least 2 pairs & at least 2 pairs & at least 1 pair & at least 1 pair & no request \\
\hline $\begin{array}{l}\text { generations } \\
\text { affected }\end{array}$ & $\begin{array}{l}\text { at least } 2 \text { successive } \\
\text { generations }\end{array}$ & no request & no request & no request & no request \\
\hline exclude FAP & yes & no request & no request & no request & no request \\
\hline \multirow[t]{6}{*}{ with any of these: } & $\begin{array}{l}\text { at least } 1 \text { should be } \\
\text { diagnosed before } \\
\text { age } 50\end{array}$ & no request & $\begin{array}{l}\text { at least } 1 \text { should } \\
\text { be diagnosed } \\
\text { before age } 50\end{array}$ & $\begin{array}{l}\text { at least } 1 \text { should } \\
\text { be diagnosed } \\
\text { before age } 50\end{array}$ & $\begin{array}{l}\text { CRC diagnosed } \\
\text { before age } 50\end{array}$ \\
\hline & & & $\begin{array}{l}\text { multiple colorectal } \\
\text { tumors (including } \\
\text { adenomas) }\end{array}$ & $\begin{array}{l}\text { multiple colorectal } \\
\text { cancers }\end{array}$ & $\begin{array}{l}\text { Multiple colorectal } \\
\text { tumors }\end{array}$ \\
\hline & & & $\begin{array}{l}\text { extracolorectal } \\
\text { cancer }\end{array}$ & $\begin{array}{l}\text { extracolorectal } \\
\text { cancer }\end{array}$ & $\begin{array}{l}\text { HNPCC-associated } \\
\text { tumours }\end{array}$ \\
\hline & & & & $\begin{array}{l}\text { right colon } \\
\text { involvement }\end{array}$ & $\begin{array}{l}\text { MSI-H pathologic } \\
\text { associated features } \\
\text { in a colorectal cancer } \\
\text { diagnosed before age } 60\end{array}$ \\
\hline & & & & & $\begin{array}{l}\text { - one with colorectal cancer } \\
\text { - one or more first } \\
\text { - or second-degree relatives } \\
\text { with HNPCC-related tumour } \\
\text { - one of the cancers being } \\
\text { diagnosed before age } 50\end{array}$ \\
\hline & & & & & $\begin{array}{l}\text { - one with colorectal cancer } \\
\text { - two or more first } \\
\text { - or second-degree relatives } \\
\text { with HNPCC-related tumour }\end{array}$ \\
\hline
\end{tabular}

Note: MSI-H pathologic associated features including the presence of tumor infiltrating lymphocytes, Crohn's-like lymphocytic reaction, mucinous/signet-ring differentiation, or medullary growth pattern

found to carry 43 germline mutations $(60 \% \mathrm{MLH} 1$ mutations and $40 \% \mathrm{MSH} 2$ mutations (Table 2). All of the genomic sites of mutations were verified by DNA sequencing. Among these mutations, 10/43 (23\%) result in a shift of transcribe reading frame. Eight out of forty-three (19\%) are nonsense mutations which lead to truncating proteins. These are obviously pathological mutations. However, missense and splice site mutations, which account for $14 / 43$ (33\%) and 7/43 (16\%), respectively, are putative mutations needing further pathological verifications. Four of the observed mutations were small nucleotide deletions, which may help in discovering the critical amino acid related functions of MMR proteins. In addition to small mutations, large genomic rearrangements of Chinese HNPCC are also investigated. Huang et al. first reported a genomic deletion ranging from exon 1 to exon 7 of MSH2 gene in a Chinese HNPCC family meeting Amsterdam criteria [24]. A recent study [25] shows that large genomic rearrangements, mostly deletions rather than duplications, were responsible for 7 out of 45 hereditary colorectal patients. These large fragment aberrations, uncovered in both $\mathrm{MSH} 2$ and $M L H 1$, indicate that large genomic rearrangements play a role in the pathogenesis of Chinese hereditary CRC patients. So far, the genetic alterations in Chinese HNPCC appear similar to those in Western countries; however, there are no data yet on the prevalence of Chinese MSH6 and PMS2 gene mutations.

In the Chinese studies, colorectal cancer patients were selected for germline mutation detection, more frequently 
Table 2. Germline MLH1 and MSH2 mutations observed in Chinese HNPCC families

\begin{tabular}{|c|c|c|c|c|c|}
\hline \multirow[t]{2}{*}{ Family } & \multirow[t]{2}{*}{ Criteria } & \multicolumn{2}{|c|}{ mutation in: } & \multirow[t]{2}{*}{ mutation type } & \multirow[t]{2}{*}{ reference } \\
\hline & & MLH1 & MSH2 & & \\
\hline C4 & Amsterdam & E18 c.2081 int T & $\begin{array}{l}\text { E15 c. } 2469 \operatorname{int} C \\
\text { c. } 2471 \text { int G } \\
\text { c. } 2578 \text { int T }\end{array}$ & $\begin{array}{l}\text { frameshift } \\
\text { frameshift } \\
\text { frameshift }\end{array}$ & [16] \\
\hline $\mathrm{Cl1}$ & Amsterdam & E13 c.2091 T>A & & nonsense & [16] \\
\hline $\mathrm{C} 13$ & Amsterdam & $\begin{array}{l}\text { El1 c.1760int T } \\
\text { c.1688 A }>C\end{array}$ & & $\begin{array}{l}\text { frameshiff } \\
\text { missense }\end{array}$ & [16] \\
\hline $\mathrm{H} 2$ & Amsterdam & E13 c.2038 C>T & & nonsense & {$[17]$} \\
\hline $\mathrm{H} 4$ & Amsterdam & E2 c.199 A > G & & missense & [18] \\
\hline H9 & Amsterdam & E1 1 c.305 del $24 b p$ & & small deletion & {$[17]$} \\
\hline $\mathrm{H} 11$ & Amsterdam & & El c. $14 \mathrm{~A}>\mathrm{C}$ & missense & [17] \\
\hline $\mathrm{H} 27$ & Amsterdam & & E3 c.617 int A & frameshift & {$[17]$} \\
\hline N8 & Amsterdam & E8 c.655 A>G & & missense & [19] \\
\hline N11 & Amsterdam & E3 c.265 G>T & & nonsense & [19] \\
\hline N14 & Amsterdam & E6 c. $545+3 \mathrm{~A}>\mathrm{G}$ & & splice point & [19] \\
\hline N23 & Amsterdam & E3 c.610 G>T & & nonsense & [19] \\
\hline N25 & Amsterdam & E8 c.677 G>A & & missense & [19] \\
\hline HW7 & Amsterdam & E14 c.2228 C>A & & nonsense & [20] \\
\hline HW5 & Amsterdam & E14 c.1588-1590 del & & small deletion & [20] \\
\hline $\mathrm{Cl}$ & Japan & E11 c.934 int A & & frameshift & {$[21]$} \\
\hline C6 & Japan & El c.21 G>C & & missense & {$[22]$} \\
\hline C8 & Japan & $\begin{array}{l}E 12 \text { c. } 1198 \mathrm{C}>\mathrm{G} \\
\text { c.1261 C>G } \\
\text { c. } 1364 \mathrm{int} \mathrm{C} \\
\text { c.1372 int C }\end{array}$ & & $\begin{array}{l}\text { missense } \\
\text { missense } \\
\text { frameshift } \\
\text { frameshift }\end{array}$ & {$[21]$} \\
\hline N18 & Japan & E9 c. $790+1 \mathrm{G}>\mathrm{A}$ & & splice point & [19] \\
\hline N26 & Japan & & E14 c.2211-2 A >C & splice point & [19] \\
\hline HW6 & Japan & $\mathrm{E} 15$ c. $1731+1 \mathrm{~A}>\mathrm{G}$ & & missense & {$[20]$} \\
\hline $\mathrm{H} 12$ & China & E15 c.2516 G>A & & missense & [18] \\
\hline $\mathrm{H} 2 \mathrm{O}$ & China & E19 c.2250 G>C & & nonsense & [18] \\
\hline H5 & $*$ & & E3 c. $425 \mathrm{G}>\mathrm{C}$ & nonsense & [23] \\
\hline $\mathrm{H} 6$ & $*$ & E15 c.1731 G>A & & splice point & [23] \\
\hline $\mathrm{H} 17$ & $*$ & E15 c.1731 G>A & & splice point & [23] \\
\hline $\mathrm{H} 45$ & $*$ & E16 c. 1846 del AAG & & small deletion & [23] \\
\hline $\mathrm{H} 47$ & $*$ & $\mathrm{E} 12 \mathrm{c} .1151 \mathrm{~T}>\mathrm{A}$ & & missense & [23] \\
\hline H52 & $*$ & E2 c.194 G>A & & missense & [23] \\
\hline $\mathrm{H} 56$ & $*$ & & E16 c.2792 A>C & missense & [23] \\
\hline H62 & ${ }^{*}$ & E14 c. 1588 del TTC & & small deletion & [23] \\
\hline $\mathrm{H} 64$ & $*$ & $\mathrm{E} 15$ c. $1731+1 \mathrm{G}>\mathrm{A}$ & & splice point & [23] \\
\hline $\mathrm{H} 65$ & $*$ & E14 c.2228 C>A & & nonsense & [23] \\
\hline $\mathrm{H} 67$ & $*$ & E14 c. $1559-2$ G >A & & splice point & [23] \\
\hline $\mathrm{H} 68$ & $*$ & $\begin{array}{l}\text { E2 c. } 137 \text { G > T } \\
\text { E1 } 1 \text { c. } 914 \text { int } 24\end{array}$ & & $\begin{array}{l}\text { missense } \\
\text { frameshiff }\end{array}$ & $\begin{array}{l}23] \\
{[23]}\end{array}$ \\
\hline
\end{tabular}

E=exon, $c=$ codon

${ }^{*}=$ clinical diagnostic criteria for each of these families are unknown, but it is clear that one of them meets the Bethesda criteria and three of them meet the Japanese criteria 
Table 3. Rates of detected germline MLH1 and MSH2 mutations in Chinese typical and suspected HNPCC patients

\begin{tabular}{llll}
\hline Clinical Criteria & positive/screened & percentage & reference \\
\hline Amsterdam & $23 / 52$ & $44 \%$ & {$[18,19,20,22,23]$} \\
\hline Japan & $8 / 24$ & $33 \%$ & {$[19,20,22]$} \\
\hline Korea/China & $5 / 23$ & $22 \%$ & {$[18]^{*}$} \\
\hline Bethesda & $1 / 19$ & $5 \%$ & {$[22]$} \\
\hline${ }^{*}$ partly based on unpublished data & & \\
\hline
\end{tabular}

using criteria for suspected HNPCC rather than the Bethesda criteria. Table 3 shows different detection rates of germline mutations in typical and suspected HNPCC families. The highest rate was observed in kindreds meeting the Amsterdam criteria, which is about 44\%, similar to that in reports from Western countries, which often quote a rate between $40 \%$ and $60 \%$. Compared with the Bethesda criteria, we prefer to use the suspected HNPCC criteria in the clinical setting of screening for HNPCC. Especially in small Chinese families we would suggest using the suspected HNPCC criteria rather than the Amsterdam criteria.

\section{Clinical manifestations}

The most striking feature of HNPCC is the predisposition for early onset and/or multiple colorectal malignancies. The mean age of onset of colorectal cancer is 44 years, approximately 20 years earlier than that for sporadic colorectal cancer. In Lynch families, colorectal cancer tends to be multiple, either synchronously (18\%) or metachronously (24\%) [26]. Other features of HNPCC involve proximal location of CRC, mucinous or poorly differentiated histology, and better prognosis. Previous studies [16, 27-48] have shown features of colorectal cancer in Chinese HNPCC patients (Table 4). With a few exceptions, clinical manifestations of Chinese HNPCC colorectal cancer are largely the same as those described above. However, the involvement of rectal cancer in HNPCC is the most interesting exception. Contrary to sporadic CRC in the Western world, more than half of colorectal cancer in China is rectal cancer rather than colon cancer. But this distribution does not exist in colorectal cancer in HNPCC families. Although they account for less than half of all cases of colorectal cancer, rectal cancer in Lynch families is considerably reduced compared with sporadic CRCs. This may indicate differences in oncogenetic pathways between HNPCC and sporadic CRCs.

Lynch syndrome is associated with a wide spectrum of cancers. The pattern of cancers has changed over time.
Previous studies [49] indicate that there are several ways to verify whether or not a particular tumour may be associated with HNPCC. A demonstrated increase in risk of developing a particular tumour type in HNPCC families (or better, proven mutation carriers) is the classical approach taken. Based on these principles, the recent Bethesda conference advised that colorectal, endometrial, gastric, ovarian, small bowel, hepatobiliary, ureter and renal pelvis cancer should be included in the HNPCCassociated tumour spectrum [10]. However, the tumour spectrum of HNPCC families from Western countries is quite different to that from the Far East. This reflects the variation in incidence of cancers in the respective populations. For example, gastric cancer instead of endometrial cancer is the second most common cancer in Chinese Lynch syndrome families. Among 30 Amsterdam families, 10 out of 27 extracolonic malignancies involved gastric cancer, much more than the 4 cases of endometrial cancer [50]. Because no difference in clinical manifestation between HNPCCassociated gastric cancer and familial gastric cancer has been found [51], further studies of germline mutations of HNPCC-associated gastric cancer are needed.

\section{Management and surveillance}

Identification of families with HNPCC syndrome based on exact clinical information is inefficient according to the genetic definition of HNPCC. Even when the original Amsterdam criteria are met in a family, the likelihood of detecting a germline mismatch repair gene mutation is only $40-60 \%$ [52]. However, one of the main benefits of genetic analysis is the identification of mutation negative family members in a positive pedigree, since it frees the individual from anxiety and unnecessarily frequent surveillance. An algorithm (Fig. 1) for the genetic screening of individuals suspected for HNPCC has been established by the National Hereditary Colorectal Cancer Network of China [13]. Microsatellite instability (MSI) and immunohistochemistry (IHC) testing for MMR 
Table 4. Features of colorectal cancer In Chinese HNPCC and sporadic CRC patients

\begin{tabular}{|c|c|c|c|c|}
\hline & $\begin{array}{l}\text { Amsterdam criteria } \\
\text { cases (\%) }\end{array}$ & $\begin{array}{l}\text { Japanese criteria } \\
\text { cases (\%) }\end{array}$ & $\begin{array}{l}\text { Chinese/Korean criteria } \\
\text { cases (\%) }\end{array}$ & $\begin{array}{l}\text { Sporadic CRC } \\
\text { cases (\%) }\end{array}$ \\
\hline \multicolumn{5}{|l|}{ 1. Gender } \\
\hline male & $166(55)$ & $53(48)$ & $14(33)$ & 437 (47) \\
\hline female & $136(45)$ & $57(52)$ & $28(67)$ & $50(53)$ \\
\hline \multicolumn{5}{|l|}{ 2. Location } \\
\hline right colon & $85(40)$ & $33(26)$ & $144(10)$ & \\
\hline other colon & $155(73)$ & $65(52)$ & $26(62)$ & 540 (39) \\
\hline rectum & $57(27)$ & $60(48)$ & $16(38)$ & $853(61)$ \\
\hline \multicolumn{5}{|l|}{ 3. Duke's stage } \\
\hline$A \& B$ & $67(63)$ & $42(46)$ & $34(81)$ & $387(49)$ \\
\hline$C \& D$ & $40(37)$ & $49(54)$ & $8(19)$ & $400(51)$ \\
\hline \multicolumn{5}{|l|}{ 4. Differentiation } \\
\hline low grade & $17(40)$ & $24(39)$ & $5(13)$ & 108 (14) \\
\hline high grade & $25(50)$ & $38(61)$ & $34(87)$ & $664(86)$ \\
\hline \multicolumn{5}{|l|}{ 5. Multiple malignancy } \\
\hline total & $25(9)$ & $19(15)$ & $6(14)$ & $25(3)$ \\
\hline synchronous & $5(2)$ & $11(9)$ & & \\
\hline metachronous & $20(7)$ & $8(6)$ & & \\
\hline not multiple & $260(91)$ & $110(85)$ & $36(86)$ & $867(97)$ \\
\hline \multicolumn{5}{|l|}{ 6. Adenomas } \\
\hline with adenomas & $13(18)$ & $6(21)$ & $98(18)$ & \\
\hline without adenomas & $58(82)$ & $23(79)$ & $450(82)$ & \\
\hline
\end{tabular}

genes in tumour tissue is used as a complementary screening method. Individuals with negative results are excluded from further genetic testing.

Once suspected HNPCC has been diagnosed, $7.10 \mathrm{ml}$ of peripheral blood of the patient are collected. $3 \mathrm{ml}$ of this sample are used for white blood cell immortalization, and the rest is stored in a $-20^{\circ} \mathrm{C}$ refrigerator for further study. Subsequently, clinical screening takes place, including detailed endoscopic examination of the whole gastrointestinal tract, followed by ultrasound screening of the pelvis and hepatobiliary organs. A regular surgical operation is performed if a tumour is detected. Although multiple malignancies in the colon and rectum are not infrequent in HNPCC, prophylactic colectomy is still not recommended. Recent studies [53] show that HNPCC colorectal cancers, which are usually microsatellite intsable, are insensitive to 5-FU-based chemotherapic regimens; however, adjuvant chemotherapy after colonectomy is still routinely prescribed.

For patients with cancer or affect individuals with a definitive inherited mutation, interval surveillance is recommended for colorectal, gastric and endometrial cancer. Data have shown [54] that lifetime risks for colorectal, gastric and endometrial cancer in Chinese
HNPCC are $93.3 \%, 28.1 \%$ and $23.3 \%$ respectively. Although these cancer risks might be overestimated, surveillance for these malignancies is necessary. Considering the early onset of HNPCC malignancies and the tendency for proximal and metachronous colon lesions, full colonoscopy is recommended every one to two years beginning between the ages of 20 and 25. Removal of polyps can also be undertaken during endoscopic examination, which likely reduces the risk of colorectal cancer and may prolong survival. Other reasonable approaches involve transvaginal ultrasound or endometrial aspiration with cytology to screen for endometrial cancer and gastroendoscopy for gastric cancer, based on available evidence and expert opinions.

\section{Familial adenomatous polyposis (FAP)}

FAP is an autosomal dominantly inherited disease with almost $100 \%$ penetrance characterised by the presence of hundreds to thousands of small adenomatous polyps, which if left untreated would almost certainly develop into colorectal cancer. Mutations in the adenomatous polyposis coli (APC) gene are responsible for the syndrome. In addition, several variants of the syndrome exist, namely Gardner syndrome, Turcot 
syndrome and attenuated adenomatous polyposis (AAPC or AFAP). Compared with HNPCC, fewer research papers have been published on FAP in China.

\section{Incidence}

In China, of all colorectal cancer, only $0.94 \%$ is due to FAP. According to a survey executed twenty years age in a county in the south-east of China, the incidence of FAP in 18,950 individuals above age 30 was estimated to be approximately 1.5/100,000 [55]. However, this was an outcome after screening by $15 \mathrm{~cm}$ rectum endoscopy; therefore the real incidence in this county would probably be a little higher.

\section{Clinical features}

The hallmark of FAP is the growth of profuse adenomatous colorectal polyps at a young age. Diarrhoea, gastrointestinal bleeding and abdominal pain caused by polyps lead to the diagnosis. The polyps in FAP have a slight predisposition for the distal colon. However, the most important feature in Chinese FAP is the incidence of rectum polyps. Among 42 FAP patients in their first visit to the hospital, 30 were found to have polyps in rectums simply by anal and rectum check by finger, which finally led to the diagnosis of FAP [56]. Polyps can emerge in FAP patients as young as 16 months in China [57]. The number and size of these polyps increases with time, ultimately reaching the number of hundreds to thousands. If left untreated, nearly all patients with this disorder will ultimately develop colorectal cancer due to the vast number of polyps. Liu Jian et al. [55]collected 50 FAP families in the 1979-1993 period. FAP was diagnosed at the average age of 31 years. Sixty-four percent of the patients had developed colorectal cancer. After endoscopic screening of 57 first-degree relatives, another 18 FAP patients, with an average age of 19 years were uncovered. Only $5.65 \%$ of these new-found FAP cases had developed colorectal cancer, significantly lower than that of the index cases. This shows that cancer risk for Chinese FAP increases rapidly in the course of time, especially during the third and fourth decades of life. As in Western populations, age is the determinant of cancer risk in Chinese FAP patients as well.

\section{APC gene mutation}

Mutations in the APC gene are responsible for this syndrome. In most cases, one allele with the mutated gene is inherited from an affected parent. An acquired (somatic) mutation in the other APC allele results in the

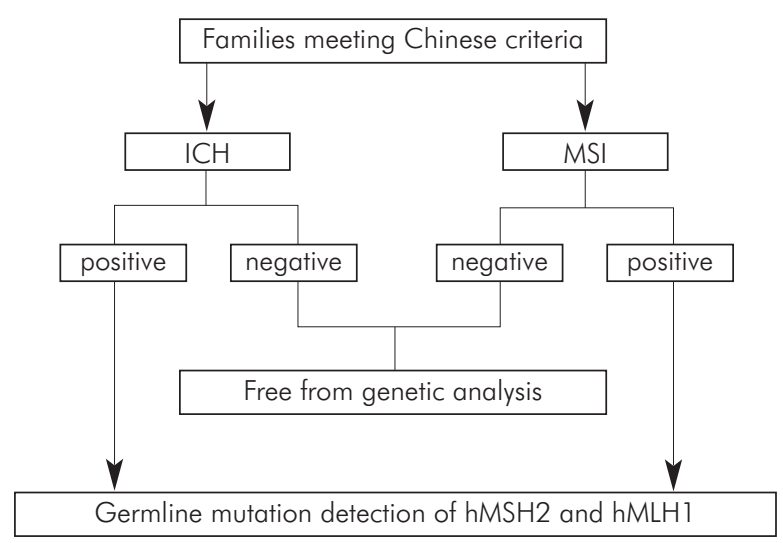

Fig. 1. Genetic Screening Strategy for HNPCC in China

development of adenomas. However, a lack of family history can be observed in one third of cases, which is explained by de novo germline mutations. It has been reported that an APC gene mutation can be detected in 80-90\% of FAP patients [58]. Gan Yuebo et al. [59] first reported an APC germline mutation in Chinese FAP patients in 1994. One out of 7 APC families was found to have an AAAGA nucleotide deletion in codon 1309-1311. Recently, studies on the large exon 15 of APC were reported. Five out of 22 FAP pedigrees were found to have germline mutations in this exon, all them being frameshift mutations [60]. Another study reported 6 out of 18 FAP patients having germline mutations on 4 fragments in exon 14 and 15 [61]. Recently, germline mutations in the MYH gene have been identified as another cause of adenomatous polyposis. The role of MYH in Chinese (A) FAP has not been studied yet.

\section{Management and prevention}

After the clinical diagnosis of FAP, prophylactic colostomy is recommended. However, the optimal timing for this procedure is difficult to specify. The balance between disease progression and the adolescent's physical and psychosocial maturity should be considered. Presently, the surgical methods in China involve total resection of the colon and rectum with permanent ileostomy, ileorectal anastomosis, ileal pouch-anal anastomosis, subtotal colectomy plus rectal polyposis electrocautery and anastomosis of the caecum and anus preserving the ileocecal valve [56, $57,62]$. However, no significant prevalence differences have been observed among these methods, because surgical outcomes depend on the skill of the surgeon and the appropriateness of the surgical method rather than personal preference. 
Patients with FAP also develop adenomatous polyps in the upper gastrointestinal tract. Duodenal and ampullary polyps pose obstacles for treatment due to surgical risks. The anti-COX2 agent celexib was recently reported to have successfully prevented development of upper gastrointestinal tract polyps in two Chinese FAP patients [63]. A male and a female, both 20 years old, both with germline APC gene mutations, each had 15 41 polyps in their duodenal tract. After administration of celexib $400 \mathrm{mg}$ twice per day for 12-24 months, the numbers of duodenal polyps decreased to 0-3. After electrocautery removal of the remaining polyps, both patients are free from duodenal polyps. Nonetheless, a tricky thing in these cases is the effect of anti-COX2 agent on colorectal rather than duodenal polyps, because no significant improvement has been observed in colorectal polyps in both cases. Another strategy, using sulindac to prevent the development of polyps, was used in 18 Chinese FAP cases [64]. Although both a reduction of numbers and an improvement of histopathology are observed in colorectal polyps after 12 months of administration, the difficulty remains that usually 3-6 months after stopping the administration of the drug polyps recur. A similar result was reported in Western countries. The chemopreventive effects of both NSAID and anti-COX2 agents on FAP still need further study.

\section{Hamartomatous polyposis syndromes}

Hamatomatous polyposis in the gastrointestinal tract mainly includes juvenile polyposis and Peutz-Jeghers syndrome (PJS). Few reports can be found on Chinese juvenile polyposis, but Peutz-Jeghers syndrome does not seem to be very rare in the Chinese population. A clinical analysis for 165 typical Chinese Peutz-Jeghers cases, which were collected over the past 10 years, was reported last year [65]. It was found that hamartomatous polyps of the gastrointestinal tract and freckling of the lips and buccal mucosa were the two main features of Chinese PJS. Abdominal pain and gastrointestinal bleeding were the main presentations and $58.7 \%$ of patients with abdominal pain suffered from acute intestinal obstructions. Hamartomatous polyposis is associated with a significantly increased cancer risk. In this report, 33 patients $(20 \%)$ developed cancer, including 14 cases of colorectal cancer, 5 of gastric cancer and 3 of small bowel and cervix cancer. Cancers often developed at an early age and tended to be of low differentiation.

\section{Conclusion}

More and more papers on Chinese hereditary colorectal cancer are being published. Genetic patterns, clinical manifestations and management of Chinese hereditary colorectal cancer have been studied. HNPCC in the Chinese population, using national criteria for suspected HNPCC, appears to have a similar genetic background when compared with HNPCC in Western countries. However, a different tumour spectrum has been observed. Gastric cancer instead of endometrial cancer is the second most common cancer in Chinese HNPCC. Although rectal cancer is the major manifestation of sporadic colorectal cancer in China, no such preference has been observed in Chinese HNPCC patients. This suggests differences in gene-environment interaction between the two groups, which need to be further explored. The genetic background of Chinese familial adenomatous polyposis is less clear, but the management and preventative strategies of FAP are more accessible. Insight into the genetic and clinical features of both types of hereditary colorectal cancer in the Chinese population will help to prevent and manage these disorders.

\section{References}

1. Yang L, Parkin DM, Li LD, Chen YD and Bray F. Estimation and projection of the national profile of cancer mortality in China: 1991-2005. Br J Cancer 2004; 90 (1 1): 2157-2166.

2. Epidemiology department of Shanghai Cancer Institute incidence of malignant neoplasia in urban area of Shanghai in 1999. ZHONGLIU 2002; 22: 259.

3. Yutang G, Lu S and Yongbin X. Cancer incidence trend in Shanghai 1972-1994. ZHONGLIU 1999; 19: 255.

4. Lynch HT and de la Chapelle A. Hereditary colorectal cancer. N Engl J Med 2003; 348: 919-932.

5. Boland CR and Troncale FJ. Familial colonic cancer without antecedent polyposis. Ann Intern Med 1984; 100: 700-701.

6. Peilian L and Lianhua L. A colon cancer family with 5 cases. Ai Zheng 1984; 3: 217

7. Yaping W, Friedl W and Propping P. Germline mutation analysis in $\mathrm{hMLH} 1$ and $\mathrm{hMSH} 2$ genes in hereditary nonpolyposis colorectal cancer and colorectal cancer patients with familial history. Zhonghua Yi Xue Yi Chuan Xue Za Zhi 1998; 8: 333-336.

8. Zhang YZ, Sheng JQ, Li SR and Zhang H. Clinical phenotype and prevalence of hereditary nonpolyposis colorectal cancer syndrome in Chinese population. World J Gastroenterol 2005; ndan, Li I. † neoplasia in urbua-Bodnar, C. Szczylikka jajnikaegu zespołu von Hoppel-Lindau 1 1: 1481-1488.

9. Rodriguez-Bigas MA, Boland CR and Hamilton SR. National Cancer Institute workshop on hereditary nonpolyposis colorectal cancer syndrome: Meeting highlights and Bethesda guidelines. J Natl Cancer Inst 1997; 89: 1758-1762.

10. Umar A, Boland CR, Terdiman JP, Syngal S, de la Chapelle A, Ruschoff J, Fishel R, Lindor NM, Burgart LJ, Hamelin R, Hamilton SR, Hiatt RA, Jass J, Lindblom A, Lynch HT, Peltomaki P, Ramsey SD, Rodriguez-Bigas MA, Vasen HF, Hawk ET, Barrett JC, Freedman AN and Srivastava S. Revised Bethesda Guidelines for hereditary nonpolyposis colorectal cancer (Lynch syndrome) and microsatellite instability. J Natl Cancer Inst 2004; 96: 261-268.

11. Fujita S, Moriya Y, Sugihara K, Akasu T and Ushio K. Prognosis of hereditary nonpolyposis colorectal cancer (HNPCC) and the role of Japanese criteria for HNPCC. Jpn J Clin Oncol 1996; 26: 351-355. 
12. Park JG, Vasen HF, Park KJ, Peltomaki P, Ponz de Leon M, RodriguezBigas MA, Lubinski J, Beck NE, Bisgaard ML, Miyaki M, Wijnen JT, Baba S and Lynch HT. Suspected hereditary nonpolyposis colorectal cancer: International Collaborative Group on Hereditary Non-Polyposis Colorectal Cancer (ICG-HNPCC) criteria and results of genetic diagnosis. Dis Colon Rectum 1999; 42: 710-715.

13. National Hereditary Colorectal Cancer Network. Screening program of Chinese hereditary colorectal cancer. Chin J Oncol 2004; 26: 191-192.

14. Peltomaki P and Vasen H. Mutations associated with HNPCC predisposition. Update of ICG-HNPCC/INSiGHT mutation database. Dis Markers 2004; 20: 269-276.

15. van der Klift H, Wiinen J, Wagner A, Verkuilen P, Tops C, Otway R, Kohonen-Corish M, Vasen H, Oliani C, Barana D, Moller P, Delozier-Blanchet C, Hutter P, Foulkes W, Lynch H, Burn J, Moslein $G$ and Fodde R. Molecular characterization of the spectrum of genomic deletions in the mismatch repair genes MSH2, MLH1, MSH6, and PMS2 responsible for hereditary nonpolyposis colorectal cancer (HNPCC). Genes Chromosomes Cancer 2005; 44: 123-138.

16. Jin H, Cui L and Meng R. Study of germline mutation of hM LHI and hM SH2 in Chinese kindreds of hereditary nonpolyposis colorectal cancer. Chin J Gastrointest Surg 2002; 5: 126-129.

17. Cai Q, Sun M, Lu H, Zhang T, Mo S, Xu Y, Cai S, Zhu Z and Shi R. Clinicopathological and molecular genetic analysis in Chinese typical hereditary nonpolyposis colorectal cancer pedigrees. Chin J Pathol 2001; 30: 339-344.

18. Huang Y, Yuan Y, Wang Y, Zhu M, Zhang S and Zheng S. Mutation detection of mismatch repair genes in hereditary nonpolyposis colorectal cancer by denaturing high-performance liquid chromatograph. Chin J Surg 2005; 43: 317-320.

19. Liu SR, Zhao B, Wang ZJ, Wan YL and Huang YT. Clinical features and mismatch repair gene mutation screening in Chinese patients with hereditary nonpolyposis colorectal carcinoma. World J Gastroenterol 2004; 10: 2647-2651.

20. Luo DC, Cai Q, Sun MH, Ni YZ, Tao CW, Chen ZJ and Shi DR. Clinical analysis and molecular genetic study of hereditary nonpolyposis colorectal cancer kindreds. Zhonghua Wai Ke Za Zhi 2004; 42: 158-162.

21. Cui L, Jin HY, Cheng HY, Yan YD, Meng RG and Yu DH. Genetic detection of Chinese hereditary nonpolyposis colorectal cancer. World J Gastroenterol 2004; 10: 209-213.

22. Cui L, Jin $H$, Meng R, Yan Y, Wang J, Liu F, Xu H and $Y u$ D. Clinicopathological features of typical and nontypical hereditary non-polyposis colorectal cancer and their germline mutation of hMLH and hMSH2. Chin J Surg 2003; 41: 113-115.

23. Cai Q, Sun M, Fu G, Ding C, Mo S, Cai S, Ren S and Ming D. Mutation analysis of hMSH2 and hM LH1 genes in Chinese hereditary nonpolyposis colorectal cancer families. Chin J Pathol 2003; 32: 323-328.

24. Haung YQ, Yuan Y, Wang YP, Zhu M, Zhang SZ and Zheng S. Large genomic deletions of mismatch repair genes in Chinese patients with hereditary nonpolyposis colorectal cancer. Zhonghua Yi Xue Yi Chuan Xue Za Zhi 2005; 22: 88-90.

25. Zhu M, Li J, Zhang X, Liu X, Friedl W, Zhang Y, Wu X, Propping $P$ and Wang $Y$. Large genomic aberrations in MSH2 and MLH1 genes are frequent in Chinese colorectal cancer. Cancer Genet Cytogenet 2005; 160: 61-67.

26. Jass JR and Stewart SM. Evolution of hereditary nonpolyposis colorectal cancer. Am J Med 1992; 33: 783-786.

27. Song YM and Zheng S. Analysis for phenotype of HNPCC in China. World J Gastroenterol 2002; 8 (5): 837-840.

28. Cai Q, Sun M, Lu H, Zhang T, Mo S, Xu Y, Cai S, Zhu X and Shi D. Clinicopathological and molecular genetic analysis in Chinese typical hereditary nonpolyposis colorectal cancer pedigrees. Zhonghua Bing Li Xue Za Zhi 2001; 30: 339-344.

29. Liu F, Ding Y and Wu K. 10 cases report of untypical hereditary nonpolyposis colorectal cancer. Clinical Medicine of China 2002; 18: 147-148.

30. Jin H, Cui L, Meng R and Yan Y. The clinicopathological features of 19 nontypical pedigrees of hereditary nonpolyposis colorectal cancer. J Surg Concepts Pract 2001; 6: 398-399.

31. Jin H, Liu F, Meng R, Ding Y and Yu D. The features and clinical roles of the mutation of BAT-26 and BAT-25 in patients with HNPCC. Chin J Exp Surg 2003; 20: 879-880.

32. Xu N, Qiu H, Ding Y and Xu Li. MSI - a useful molecular indicator of hereditary nonpolyposis colorectal cancer: a report of 4 cases. J First Mil Med Univ 1999; 19: 160-162.

33. Jian $Y, W_{u} B$, Zhang $Y$ and Zhou D. Hereditary nonpolyposis colorectal cancer: analysis of 5 families. J First Mil Med Univ $2001 ; 21: 15-16$.

34. Xu S, Mo S and Cai Hong. Hereditary nonpolyposis colorectal cancer: a report of 3 families. China Oncology 1998; 8: 56-58.

35. Chen G. Hereditary nonpolyposis colorectal cancer: a report of 27 cases in 10 families. China Clinical Oncology 2003; 30: 247-249.

36. Shao $W$ and $X i X$. Hereditary nonpolyposis colorectal carcinoma: report of 5 familial HNPCC. J Chin Gastroenternol 2001; 21 : 27-29.

37. Luo D, Ni Y, Mo S, Tao C and Chen Z. Hereditary nonpolyposis colorectal cancer: a report of 27 cases in 10 families. Chin J Gen Surg 2003; 18: 594-596.

38. Huang J. Clinical features of hereditary nonpolyposis colorectal cancer. Chin J Surg 2001; 39: 442-445.

39. Xue Z and Zheng K. Management and survellance of hereditary nonpolyposis colorectal cancer. Guangdong Medical Journal 2003; 24: 752-753.

40. Jin H, Feng C, Yao J, Huang M and Fu R. The frequency and clinicopathologic characteristics of hereditary nonpolyposis colorectal carcinomas. Chin J Prac Surg 2000; 20: 231-232.

41. Wang S, Gu G and Ding Y. An analysis on diagnosis of hereditary nonpolyposis colorectal cancer or suspected hereditary nonpolyposis colorectal cancer. Zhong Liu Xue Za Zhi 2002; 8: 24-26.

42. Sheng J, Shen Z and Fan C. Clinical phenotypes of hereditary nonpolyposis colorectal cancer in Chinese population. Natl Med J Chin 2002; 82: 1371-1374.

43. Liu H. A study on the family history and clinical features of hereditary nonpolyposis colorectal cancer. Chin J Gen Surg 2002; 17: 711-713.

44. Xu Y, Cai S, Mo S, Guan Z, Sun M, Cai Q and Shi R. Characteristics of hereditary nonpolyposis colorectal cancer among Chinese patients. Chin J Dig 2002; 22: 157-159.

45. Liu L, Liu S and Gong E. Analysis of the features of extracolonic tumor in hereditary nonpolyposis colorectal cancer. Zhong Guo Mei Tan Gong Ye Yi Xue Za Zhi 2002; 5: 643-644.

46. Wang Z, Wan Y, Liu Y and Huang Y. Diagnosis, treatment and follow-up of 9 hereditary nonpolyposis colorectal cancer pedigrees. Chin J Gastrointenst Surg 2003; 3: 217-219.

47. Sheng J, Li S and Mu H. Clinical analysis of hereditary nonpolyposis colorectal cancer. World J Chin Dig 2002; 10: 104-105.

48. Luo D, Ni Y, Mo S and Chen Z. Hereditary nonpolyposis colorectal cancer: a report of 4 families. China Oncology 2000; 10: $145-147$

49. Watson $P$ and Riley B. The tumor spectrum in the Lynch syndrome. Fam Cancer 2005; 4: 245-248.

50. Cai SJ, Xu Y, Cai GX, Lian P, Guan ZQ, Mo SJ, Sun MH, Cai Q and Shi DR. Clinical characteristics and diagnosis of patients with hereditary nonpolyposis colorectal cancer. World J Gastroenterol 2003; 9: 284-287. 
51. Cui L, Jin H, Meng R, Zhang X, Yan Y and Yu D. The features of gastric cancer in hereditary nonpolyposis colorectal cancer family and analysis of its significance in screening of HNPCC kindreds. J Surg Concepts Pract 2003; 8: 482-484.

52. Grady WM. Genetic testing for high risk colon cancer patients. Gastroenterology 2003; 124: 1574-1594.

53. de Vos tot Nederveen Cappel WH, Meulenbeld HJ, Kleibeuker $\mathrm{JH}$, Nagengast FM, Menko FH, Griffioen G, Cats A, Morreau $H$, Gelderblom H and Vasen HF. Survival after adjuvant 5-FU treatment for stage III colon cancer in hereditary nonpolyposis colorectal cancer. Int J Cancer 2004; 109: 468-471.

54. Jin HY, Yan HL, Ma XQ, He Y, Ding YJ, Meng R-G, Yan YD and Cui L. Cancer spectrum and cumulative lifetime risk for hereditary nonpolyposis colorectal cancer in Chinese. Acad J Sea Mil Med Univ 2004; 25: 133-135.

55. Liu J, Zheng S, Feng Y, Yu H and Yang G. Familial adenomatous polyposis registry and report of a survey. Chin J Oncol 1997; 19: 416

56. Xue $Y$, Wang $H, F u W, W u Z$ and $Y u D$. Discuss on surgical methods of 42 familial adenomatous polyposis. Medical Journal of the Chinese People's Armed Police Forces 2002; 13: 482.

57. Wen Y, Lu J, Zhu M, Wu Ch, Li L and Zhu W. Surgical treatment of familial adenomatous polyposis: a report of 45 cases. Chin J Gen Surg 2004; 13: 673-675.

58. Powell SM, Petersen GM, Krush AJ, Booker S, Jen J and Giardiello FM. Molecular diagnosis of familial adenomatous polyposis. N Engl J Med 1993; 329: 1982-1987.

59. Gan Y, Zheng S, Cai X, Liu J and Geng L. Detection of a gene mutation in familial adenomatous polyposis families by PCR-RFLP method. Zhonghua Yi Xue Za Zhi 1994; 6: 352-354

60. Liu XR, Shan XN, Friedl W, Uhlhaas S, Li JT, Propping P and Wang YP. Detection of germline mutations in the APC gene with the protein truncation test. Yi Chuan Xue Bao 2005; 32: 903-908.

61. Jiao Y, Gong E, Meng G, Liu S, E Wen and Ding Y. Detection of APC gene germline mutations in familial adenomatous polyposis patients. Beiijing Yi Ke Da Xue Xue Bao 1997; 28: 267-269.

62. $\mathrm{Xu} H$ and $X i a o J Q$. Anastomosis of the cecum and anus preserving the ileocecal valve through the rectal muscular cuff for benign colorectal diseases. Di Yi Jun Yi Da Xue Xue Bao 2005; 25: 599-600.

63. Wang J and Luo M. Treatment of upper gastrointestinal polyps in familial adenomatous polyposis with celexib. Chin J Surg 2003; 43: 196

64. Li J, Lu Y, Gu F, An Y, Qian Y. The long-term effects of sulindac on familial adenomatous polyposis. Chin J Dig 2005; 25: 153-156.

65. Yang B, Zhao B, Wang Z. Clinical Features and Management of Peutz-Jeghers Syndrome. J Colo Surg 2004; 10: 271-273. 